\title{
A Smooth LVRT Control Strategy for Single-Phase Two-Stage Grid-Connected PV Inverters
}

\author{
Furong Xiao ${ }^{*}$, Lei Dong ${ }^{\dagger}$, Shahnawaz Farhan Khahro ${ }^{* *}$, Xiaojiang Huang*, and Xiaozhong Liao* \\ ${ }^{*}$ School of Automation, Beijing Institute of Technology, Beijing, China \\ ${ }^{* *}$ Deputy Director (Alternative Energy), Energy Department, Government of Sindh, Karachi, Pakistan
}

\begin{abstract}
Based on the inherent relationship between dc-bus voltage and grid feeding active power, two dc-bus voltage regulators with different references are adopted for a grid-connected PV inverter operating in both normal grid voltage mode and low grid voltage mode. In the proposed scheme, an additional dc-bus voltage regulator paralleled with maximum power point tracking controller is used to guarantee the reliability of the low voltage ride-through (LVRT) of the inverter. Unlike conventional LVRT strategies, the proposed strategy does not require detecting grid voltage sag fault in terms of realizing LVRT. Moreover, the developed method does not have switching operations. The proposed technique can also enhance the stability of a power system in case of varying environmental conditions during a low grid voltage period. The operation principle of the presented LVRT control strategy is presented in detail, together with the design guidelines for the key parameters. Finally, a $3 \mathrm{~kW}$ prototype is built to validate the feasibility of the proposed LVRT strategy.
\end{abstract}

Key words: Low grid voltage mode, Low voltage ride-through, Normal grid voltage mode, Single-phase Grid-connected PV inverter

\section{INTRODUCTION}

Low voltage ride-through (LVRT) and dynamic voltage supporting (DVS) of grid-connected PV systems are increasingly becoming important along with the increasing penetration of photovoltaic (PV) systems. A sudden disconnection of all PV systems from a power grid triggers severe problems, such as power outages and voltage flickers [1], [2]. To enhance the stability of a power grid during a sudden grid voltage drop, some relevant standards require large-capacity PV systems to allow LVRT [3]-[5]. The LVRT standard of China for PV systems is shown in Fig. 1(a). Evidently, all generating plants are required to remain connected with the grid when the grid voltage is within the shaded area known as LVRT. Aside from maintaining connection, the PV system is required to provide reactive power to participate in grid voltage control during fault period

Manuscript received Nov. 4, 2014; accepted Feb. 11, 2015

Recommended for publication by Associate Editor Sung-Yeul Park.

†Corresponding Author: correspondent_dong@163.com

Tel: +86-13910861946, Beijing Institute of Technology

*School of Automation, Beijing Institute of Technology, China

** Deputy Director (Alternative Energy), Energy Department, Government of Sindh, Pakistan and during the recovery process of the after-fault period known as DVS [6], [7]. The E.ON code requires the PV system to provide a linearly proportional active/reactive current output when the grid voltage varies in the range of $50 \%$ to $90 \%$ nominal voltage. When the grid voltage drops below $50 \%$, the PV system should produce $100 \%$ reactive current. The required percentage of reactive current during LVRT is illustrated in Fig. 1(b).

When connected to a power grid, PV inverters are susceptible to electrical disturbances, such as grid voltage variations, harmonic resonance, and waveform distortions [8], [9]. Grid voltage sag is one of the most challenging among these disturbances. During grid voltage sag, the grid feeding active power generally decreases suddenly, whereas the input PV power remains constant. Consequently, the surplus PV power should be absorbed entirely by the dc-bus capacitor, which causes the drastic increase of dc-bus voltage. If no actions are taken to address the power imbalance during the grid voltage sag period, the dc-bus overvoltage protection of the PV inverter is triggered. Subsequently, the PV inverter is disconnected from the grid.

Many methods have been developed in literature to enhance the LVRT capability of two-stage grid-connected PV inverters, 


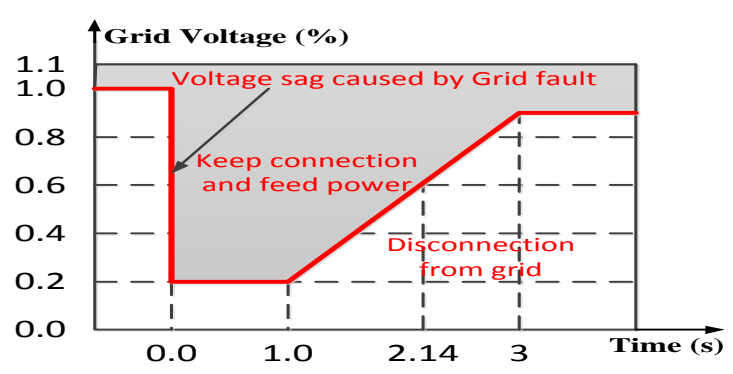

(a)

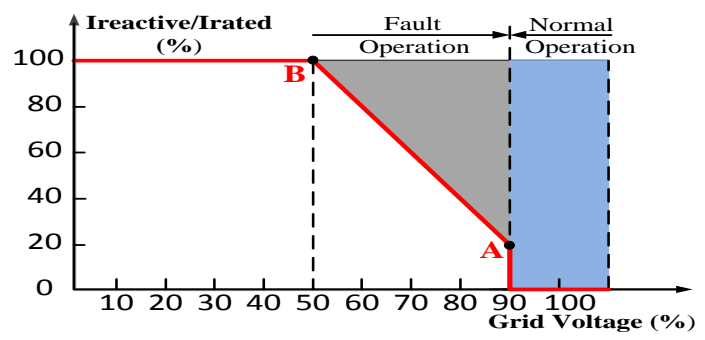

(b)

Fig. 1. LVRT requirement. (a) China: Q/GDW 617C201. (b) E.ON code for LVRT.

especially in three-phase systems. Switching from a dual-loop control to a single-loop control transfers the control system to a constant grid-connected current control for LVRT in low grid voltage mode (LGVM) from a constant power control in normal grid voltage mode (NGVM) [10]. However, such switching cannot ensure the stability of the dc-bus voltage without the outer dc-bus voltage loop in LGVM. The control system is switched to voltage control mode from the maximum power point tracking (MPPT) control mode according to the dc-bus voltage [11]. However, the different outputs of both control modes at the instant of transfer may cause current and/or voltage spikes during the switching process. The grid voltage is monitored and used to adjust the duty ratio when the ratio is reduced below the threshold [12]. Nevertheless, the grid voltage is an open-loop control and is susceptible to environmental conditions. LVRT performance is improved with a fast energy storage system based on super capacitors, but LVRT increases hardware cost significantly [13].

The aforementioned LVRT strategies in three-phase PV systems can be introduced into single-phase PV systems in terms of LVRT. Similar to Ref. [11], the control system is switched from MPPT mode to non-MPPT mode by comparing the grid feeding active power before grid voltage sag fault with the allowed maximum grid feeding active power during the fault period [14]. However, as mentioned earlier, the switching operation may cause voltage and/or current spikes at the instant of transfer. In addition, varying environmental conditions, such as the sudden decrease of solar insolation, are not considered in Ref. [14]. The LVRT strategies used for one-stage PV systems in Refs. [15] and [16] are intuitive by implementing a single-phase power control method. However, the LVRT schemes in one-stage PV systems cannot be applied to two-stage PV systems because the former do not consider the abovementioned dc-bus overvoltage problem when dealing with LVRT.

Notably, most conventional LVRT strategies rely on the detection of grid voltage sag fault. However, the nearly constant time delay in fault detection is adverse for LVRT, especially in drastic and deep voltage drop cases. Mode switching operations in conventional LVRT schemes may also cause system instability. In previous LVRT approaches, the PV inverter still abandons the MPPT function of the inverter, and then the inverter takes several minutes to restart after the fault even if the voltage sag fault only remains for several grid cycles [14]. The inverter does not only reduce solar energy harvesting, but also degrades the stability of the power system because of sudden active power drops. Furthermore, some LVRT methods cannot be used in varying environmental conditions in LGVM.

This study proposes two dc-bus voltage regulators with different references to enhance the LVRT capability of the two-stage PV system. Without detecting the voltage sag fault, no constant detection delay occurs for the realization of LVRT. Moreover, no abrupt mode switching operations exist regardless of the grid voltage sag in the presented LVRT method. Therefore, a smooth transition from NGVM to LGVM or from LGVM to NGVM is achieved in this research. The proposed LVRT technique can also adapt to varying environmental conditions in LGVM. Hence, the stability of the PV power system can be ensured even though solar insolation decreases suddenly in LGVM.

This paper is organized as follows. The proposed LVRT control scheme is illustrated in Section II. Analysis of the dc-bus voltage control in LGVM is presented in Section III, and the design of the key parameters is discussed in Section IV. The simulation and experimental results are shown in Sections $\mathrm{V}$ and VI respectively. The conclusion is presented in Section VII.

\section{PROPOSED LVRT CONTROL SYSTEM}

\section{A. Description of Control System}

A single-phase two-stage grid-connected PV system that comprises a boost chopper and a full-bridge inverter is used in this study to illustrate the proposed LVRT method, as shown in Fig. 2(a). The whole control system includes a boost chopper control system and an inverter control system, as shown in Figs. 2(b) and 2(c) respectively. As shown in Fig. 2(b), the MPPT control of PV panels and the added dc-bus voltage loop for LVRT are implemented in the boost chopper control system. Decouple control module (DCM) is adopted to decouple the MPPT controller and the PI_LVRT controller. When the output of PI_LVRT is positive, the output $S_{p v}$ of DCM is zero, otherwise the output is one. As shown in Fig. 2(c), the 


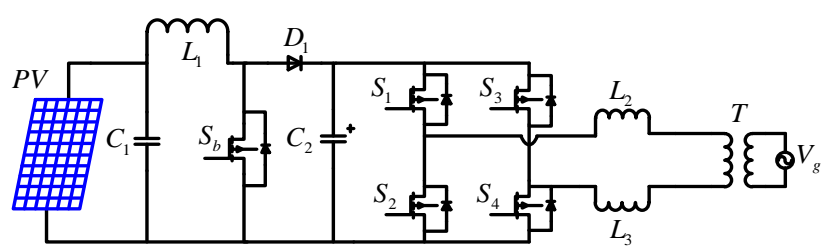

(a)

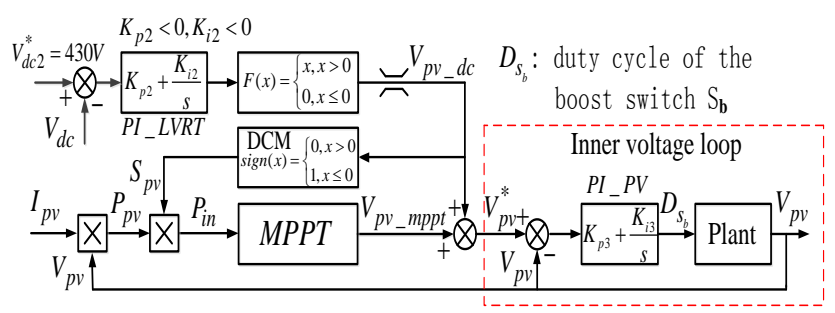

(b)

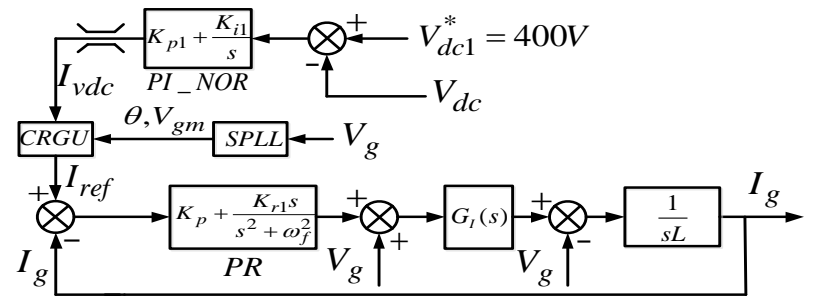

(c)

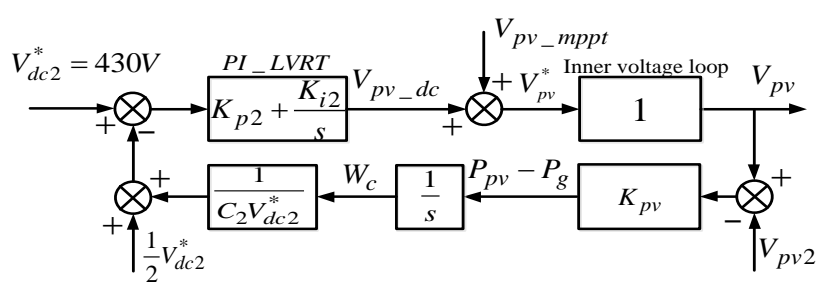

(d)

Fig. 2. (a) Single-phase two-stage grid-connected PV system. (b) Proposed boost chopper control system. (c) Inverter control system. (d) Linearized model of the dc-bus voltage control in LGVM.

classical dual-loop control is applied to the inverter control. The outer loop forces the dc-bus voltage $V_{d c}$ to track the reference $V_{d c 1}^{*}$ with the proportional-integral (PI) controller PI_NOR. In the inner current loop, the proportional-resonant (PR) controller is adopted for the high tracking capability of the sinusoidal reference of this controller. Second-order generalized integrator-based single-phase locked loop (SPLL) is implemented to measure the grid voltage amplitude and phase [17]. The grid-connected current reference is generated in the current reference generation unit (CRGU). Notably, $G_{I}(s)$ is the full-bridge model. As stated in Ref. [18], considering $G_{I}(s)$ as united when the dc-bus voltage is more than $311 \mathrm{~V}$ is reasonable in this study.

\section{B. Grid-Connected Current Reference and PV Voltage Reference}

1) Generation of Grid-Connected Current Reference in CRGU: The grid voltage is assumed to be:

$$
V_{g}=\sqrt{2} V_{g r m s} \sin \left(\omega_{f} t\right),
$$

where $V_{g r m s}$ is the grid voltage $V_{g}$ in RMS, and $\omega_{f}$ is the grid angular frequency. In NGVM, the inverter delivers all the generated PV power to the grid and maintains the dc-bus voltage at the voltage reference $V_{d c 1}^{*}$. Generally, the PV inverter supplies no reactive power for the unity power factor in normal operational modes. Therefore, the grid-connected current reference $I_{r e f}$ in NGVM is only determined by the dc-bus voltage loop and can be expressed as

$$
I_{r e f}=\sqrt{2} I_{v d c} \sin \left(\omega_{f} t\right),
$$

where $I_{v d c}$ is the output of the dc-bus voltage controller PI_NOR. In particular, the CRGU in Fig. 2(c) should be united in NGVM. Nevertheless, as mentioned in the Introduction, the grid-connected PV inverter is required to provide reactive power under grid voltage sag faults. According to Fig. 1(b), the ratio $Q_{\text {ratio }}$ between the required reactive current and the rated current $I_{r}$ of the inverter can be described as

$$
\left\{\begin{array}{lc}
Q_{\text {ratio }}=0 & V_{\text {grms }}>0.9 V_{\text {nor }} \\
Q_{\text {ratio }}=-\frac{2 V_{\text {grms }}}{V_{\text {nor }}}+2, & 0.9 V_{\text {nor }}>V_{\text {grms }}>0.5 V_{\text {nor }} \\
Q_{\text {ratio }}=1 & V_{\text {grms }}<0.5 V_{\text {nor }}
\end{array}\right\},
$$

where $V_{\text {nor }}$ is the nominal grid voltage in RMS. To prevent the inverter from triggering the overcurrent protection function at the presence of grid voltage sag, the ratio $P_{\text {ratio }}$ between the active current of the inverter to the rated current can be expressed as

$$
P_{\text {ratio }}=1-Q_{\text {ratio }} \text {. }
$$

On the one hand, to satisfy the LVRT standard of Fig. 1(b) and protect the inverter during LVRT, the required reactive current and the allowed maximum active current in LGVM should be $I_{r} P_{\text {ratio }}$ and $I_{r} Q_{\text {ratio }}$ respectively. On the other hand, the grid-connected active current command should be able to stabilize the dc-bus voltage in LGVM. Consequently, the active current command should be the minimum current of $I_{r} P_{\text {ratio }}$ and the output $I_{v d c}$ of PI_NOR. Notably, the upper limit of $I_{v d c}$ is equal to the rated current $I_{r}$ of the inverter. If $I_{v d c}$ is less than $I_{r} P_{\text {ratio }}$, then the active current command is $I_{v d c}$; otherwise, the command is $I_{r} P_{\text {ratio }}$. In addition, $I_{v d c}, I_{r} P_{\text {ratio }}$, and $I_{r} Q_{\text {ratio }}$ are all RMS values. Hence, the grid-connected current reference in LGVM can be 


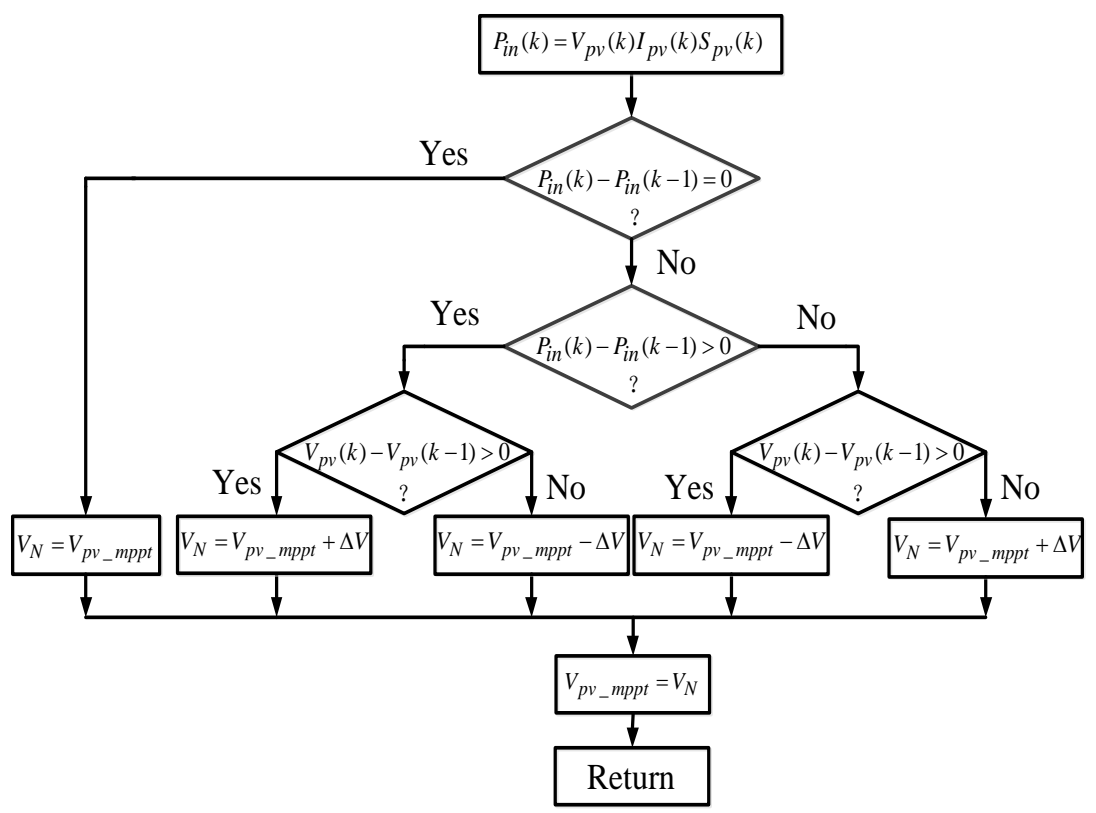

Fig. 3. P\&O flow chart.

achieved through

$$
\begin{aligned}
I_{\text {ref }} & =\underbrace{\sqrt{2} \min \left(I_{v d c}, I_{r} P_{\text {ratio }}\right) \sin \left(\omega_{f} t\right)}_{I_{p}}+\underbrace{\sqrt{2} I_{r} Q_{\text {ratio }} \cos \left(\omega_{f} t\right)}_{I_{q}} \\
& =\sqrt{2} I_{\text {grms }}^{*} \sin \left(\omega_{f} t+\varphi\right) \\
\tan (\varphi) & =\frac{I_{r} Q_{\text {ratio }}}{\min \left(I_{v d c}, I_{r} P_{\text {ratio }}\right)}
\end{aligned}
$$

where $I_{g r m s}^{*}$ represents the grid-connected current reference in RMS, $I_{p}$ and $I_{q}$ are the active and reactive current references respectively, and $\varphi$ is the phase difference between the current reference and the grid voltage.

Assuming that the grid-connected current $I_{g}$ can respond to the current command $I_{\text {ref }}$ accurately is reasonable. Therefore, from Eqs. (1) and (5), the steady-state grid feeding active power $P_{g}$ and reactive power $Q_{g}$ of the $\mathrm{PV}$ inverter in LGVM can be obtained through

$$
\begin{aligned}
& P_{g}=V_{g r m s} I_{g r m s}^{*} \cos (\varphi) \\
& Q_{g}=V_{g r m s} I_{\text {grms }}^{*} \sin (\varphi)
\end{aligned},
$$

and the allowed maximum grid feeding active power $P_{g \max }$ in LGVM is expressed as

$$
P_{\text {gmax }}=I_{r} P_{\text {ratio }} V_{\text {grms }} \text {. }
$$

2) Generation of $P V$ Voltage Reference: Clearly, the $P V$ system usually operates in the MPPT mode for maximum solar energy harvesting in NGVM. However, two operational modes for PV panels in LGVM are found in this study. If the allowable maximum grid feeding active power $P_{g \text { max }}$ is more than the present maximum power of PV panels, then the PV panels can still operate in the MPPT mode. Therefore, the whole system can operate this way in NGVM in terms of the regulation of active power (which is not the focus of this study, and is thus skipped). This study mainly focuses on analyzing the case where $P_{g \text { max }}$ is smaller than the present maximum power of PV panels. This observation implies that the dc-bus voltage is forced to increase because of the surplus PV power if the PV panels work in MPPT mode. Therefore, to ensure the power balance in LGVM, the PV panels should operate in non-MPPT mode in this case.

In NGVM, to obtain the maximum PV power, the MPPT controller should be able to track the MPP of the P-V characteristic curve of the PV panels shown in Fig. 4. Owing to its simplicity and excellent performance, perturbation and observation (P\&O) method is adopted in this study to determine the MPP by perturbing the terminal voltage of PV panels [19]. The flow chart of the P\&O method is depicted in Fig. 3. If a given perturbation $\Delta V$ leads to the increase (decrease) of PV power, the next perturbation is made in the same (opposite) direction. This way, the MPPT controller continuously seeks the maximum power point (MPP). Once the MPP is achieved, the output $V_{p v_{-} m p p t}$ of the MPPT controller approaches the PV voltage $V_{m}$ of MPP, as shown in Fig. 4.

As shown in Fig. 2(b), the PV voltage reference $V_{p v}^{*}$ can be presented as

$$
V_{p v}^{*}=V_{p v_{-} m p p t}+V_{p v_{-} d c} .
$$

Given that the output $V_{p v_{-} d c}$ of PI_LVRT is ensured to be zero in NGVM (as explained in Section II.C), the PV voltage reference equates $V_{p v_{-} m p p t}$ and eventually approaches $V_{m}$ once the MPP is determined in NGVM. 


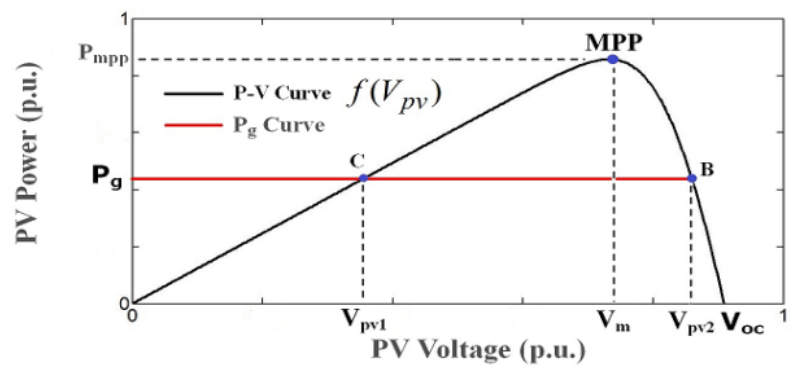

Fig. 4. P-V characteristic curve of PV panels.

As mentioned earlier, to guarantee the power balance in LGVM, the MPPT function of the PV inverter should be disabled, and the steady-state PV power should match with the grid-feeding active power $P_{g}$ calculated through Eq. (6).

Therefore, the PV panels cannot operate at the MPP, but should operate at the intersection points of the $P_{g}$ curve and the P-V characteristic curve in Fig. 4.

Fig. 4 clearly shows that the $P_{g}$ curve and the P-V characteristic curve intersect at two points B and C. Theoretically, both points B and C can be used as the steady-state operating point of PV panels in LGVM. However, most traditional DC/DC converters have an inherent negative impedance characteristic because the current of these converters increases when voltage decreases. Hence, if the PV system operates at point $\mathrm{C}$ in the left section of the $\mathrm{P}-\mathrm{V}$ characteristic curve, the terminal voltage of PV panels may collapse [19]. Given that the right section of the P-V characteristic curve is steeper than the left section, the right section may also have faster response to abrupt changes in $P_{g}$ [20]. Therefore, from the above comparison, point B in the right section of the $\mathrm{P}-\mathrm{V}$ characteristic curve is a better choice for the PV system compared with point $C$ in the left section. Thus, forcing the steady-state PV voltage reference $V_{p v}^{*}$ to approach the voltage $V_{p v 2}$ corresponding to point $\mathrm{B}$ in LGVM is better. The regulation of PV power in LGVM is implemented in the right section of the $\mathrm{P}-\mathrm{V}$ characteristic curve in this study. Hence, the PV voltage can vary between $V_{m}$ and the open-circuit voltage $V_{o c}$ in LGVM.

\section{Operation Principle of the Control System}

In NGVM, the dc-bus voltage is regulated by PI_NOR to 400 V, which forces zero output for the PI_LVRT. Therefore, based on Fig. 2(b), the PV voltage reference $V_{p v}^{*}$ is only determined by the MPPT controller in NGVM. Meanwhile, the output $S_{p v}$ of DCM becomes an output that enables the MPPT controller to seek the MPP of PV panels in NGVM.

As discussed above, the dc-bus voltage increases at the appearance of grid voltage sag. Concurrently, the output increases continuously until the upper limit is reached by the PI_NOR output. Once the dc-bus voltage reaches $430 \mathrm{~V}$, the output $V_{p v_{-} d c}$ of PI_LVRT starts to increase from zero, which forces $S_{p v}$ to become zero, turning the input to the MPPT controller into zero. Consequently, according to Fig. 3, the MPPT controller stops perturbing and output $V_{p v_{-} m p p t}$ remains constant. In particular, the PV voltage reference is only regulated by the PI_LVRT in LGVM. This finding implies that the MPPT and PI_LVRT controllers are decoupled effectively via the DCM and are not affected mutually regardless if in NGVM or LGVM. Notably, the delay time during the transient process, where the dc-bus voltage increases from $400 \mathrm{~V}$ to $430 \mathrm{~V}$, is harmful for LVRT. However, the voltage decreases as the depth of voltage sag increases. Hence, the dynamic response speed of the proposed LVRT technique increases with the increasing depth of the grid voltage sag, which is impossible in conventional LVRT approaches because of the constant time delay in grid voltage sag detection.

After the grid voltage sag fault is removed, dc-bus voltage decreases as grid feeding active power increases. Consequently, $V_{p v_{-} d c}$ decreases and PI_LVRT drops out of the dc-bus voltage control when $V_{p v_{-} d c}$ reduces to zero. Maximum PV power is then achieved instantly at the premise of constant environmental conditions because the MPPT controller always remains at the MPP of PV panels during fault period. Concurrently, DCM outputs one and PI_NOR regulates the dc-bus voltage again when $V_{d c}$ reaches $400 \mathrm{~V}$.

\section{DC-BUS VOLTAGE CONTROL IN LGVM}

\section{A. Stability Analysis of the Dc-bus Voltage Control in $L G V M$}

The case when the $P_{g \max }$ in Eq. (7) is more than the present maximum power of PV panels is used to illustrate the proposed dc-bus voltage control method in this study. As mentioned, the steady-state dc-bus voltage in LGVM is regulated by the PI_LVRT in this case. Thus, the grid-connected current reference in this case should be

$$
I_{\text {ref }}=\underbrace{\sqrt{2} I_{r} P_{\text {ratio }} \sin \left(\omega_{f} t\right)}_{I_{p}}+\underbrace{\sqrt{2} I_{r} Q_{\text {ratio }} \cos \left(\omega_{f} t\right)}_{I_{q}} .
$$

The steady-state-generated PV power $P_{p v}$ on the dc side should be identical to the grid feeding active power $P_{g}$ in terms of the power balance of the whole PV system while neglecting the power losses of the inverter. Notably, the dc-bus voltage contains double line frequency ( $2 \omega_{f}$ ) voltage ripples caused by the power pulsation on the ac side. However, the voltage ripples are generally limited to a very small size through the selection of a suitable capacitance for the dc-bus capacitor $C_{2}$ in practice. Hence, in this section, 
the double line frequency voltage ripples are not considered in the steady-state stability analysis of the dc-bus voltage control in LGVM. The stored energy $W_{c}$ in the dc-bus capacitor $C_{2}$ can be expressed as $W_{c}=\frac{1}{2} C_{2} V_{d c}^{2}$. As stated in Ref. [21], $W_{c}$ is a nonlinear term. However, when $V_{d c}$ is in the neighborhood of the reference $V_{d c 2}^{*}$ in the steady state, $W_{C}$ can be linearized as

$$
\begin{aligned}
W_{c} & =\frac{1}{2} C_{2} V_{d c}^{2}=\frac{1}{2} C_{2}\left(V_{d c 2}^{*}+\Delta V_{d c}\right)^{2} \\
& =\frac{1}{2} C_{2}\left(V_{d c 2}^{*}\right)^{2}+C_{2} V_{d c 2}^{*} \Delta V_{d c}+\frac{1}{2} C_{2}\left(\Delta V_{d c}\right)^{2}, \\
& \approx \frac{1}{2} C_{2}\left(V_{d c 2}^{*}\right)^{2}+C_{2} V_{d c 2}^{*} \Delta V_{d c} \\
& =-\frac{1}{2} C_{2}\left(V_{d c 2}^{*}\right)^{2}+C_{2} V_{d c 2}^{*} V_{d c}
\end{aligned}
$$

where $\Delta V_{d c}$ is the small difference between $V_{d c}$ and $V_{d c 2}^{*}$ in the steady state. According to Eq. (10), the steady-state dc-bus voltage can be presented as

$$
V_{d c}=\frac{W_{c}}{C_{2} V_{d c 2}^{*}}+\frac{1}{2} V_{d c 2}^{*} .
$$

Given that the stored energy of $C_{2}$ is identical to the integral of the power flowing through $C_{2}, W_{c}$ can also be achieved as

$$
W_{c}=\int\left(P_{p v}-P_{g}\right) d t
$$

The inner voltage loop in Fig. 2(b) is regarded as united when performing the analysis of the dc-bus voltage control in LGVM because of the considerably faster response speed of this loop with respect to the outer dc-bus voltage loop. In particular, the PV voltage can respond to the command $V_{p v}^{*}$ accurately. Thus,

$$
\begin{aligned}
& V_{p v_{-} d c}=K_{p 2}\left(V_{d c 2}^{*}-V_{d c}\right)+K_{i 2} \int\left(V_{d c 2}^{*}-V_{d c}\right) d t ; \\
& V_{p v}=V_{p v}^{*}=V_{p v_{-} m p p t}+V_{p v_{-} d c}
\end{aligned}
$$

with the mathematical model of the PV panels in Ref. [22], the $\mathrm{PV}$ power can be expressed in terms of the PV voltage as

$$
P_{p v}=f\left(V_{p v}\right) \text {, }
$$

where $f\left(V_{p v}\right)$ is the $\mathrm{P}-\mathrm{V}$ characteristic curve of the $\mathrm{PV}$ panels, as illustrated in Fig. 4. In a small neighborhood of the desired operating point $\mathrm{B}$ in Fig. 4, which satisfies $f\left(V_{p v 2}\right)=P_{g}$, Eq. (14) can be linearized as

$$
\begin{aligned}
P_{p v} & =f\left(V_{p v}\right)=f\left(V_{p v 2}\right)+K_{p v}\left(V_{p v}-V_{p v 2}\right) \\
& =P_{g}+K_{p v}\left(V_{p v}-V_{p v 2}\right) \\
K_{p v} & =\left(\left.\frac{d f\left(V_{p v}\right)}{d t}\right|_{v_{p v}=V_{p v 2}}\right)
\end{aligned}
$$

where $K_{p v}$ represents the slope tangential to point B of the $\mathrm{P}-\mathrm{V}$ characteristic curve. As shown in Fig. $4, K_{p v}$ is negative when $\mathrm{B}$ lies in the right region of the $\mathrm{P}-\mathrm{V}$ characteristic curve.

According to Eqs. (11)-(15), the linearized model of the dc-bus voltage control around the steady-state operating point $B$ in LGVM can be described by Fig. 2(d). The closed loop transfer function $G_{c}(s)$ of the linearized model in Fig. 2(d) can be derived as

$$
\begin{aligned}
& G_{c}(s)=\frac{\left(K_{p 2} s^{2}+K_{i 2}\right)}{s^{2}+a s+b} \\
& \left\{\begin{array}{l}
a=\frac{K_{p 2} K_{p v}}{C_{2} V_{d c 2}^{*}}=\frac{K_{p 2}}{C_{2} V_{d c 2}^{*}}\left(\left.\frac{d f\left(V_{p v}\right)}{d t}\right|_{V_{p v}=V_{p v 2}}\right) . \\
b=\frac{K_{i 2} K_{p v}}{C_{2} V_{d c 2}^{*}}=\frac{K_{i 2}}{C_{2} V_{d c 2}^{*}}\left(\left.\frac{d f\left(V_{p v}\right)}{d t}\right|_{V_{p v}=V_{p v 2}}\right)
\end{array}\right.
\end{aligned}
$$

As stated in Section II.B, the regulation of PV power for power balancing in LGVM is implemented in the right section of the $\mathrm{P}-\mathrm{V}$ characteristic curve of $\mathrm{PV}$ panels in this research. Thus, the PV power should be reduced by increasing the PV voltage $V_{p v}$ from Fig. 4 if $V_{d c}>V_{d c 2}^{*}$. Hence, according to Eq. (13), $K_{p 2}$ and $K_{i 2}$ are set as negative, such that $V_{p v_{-} d c}$ can increase when $V_{d c}>V_{d c 2}^{*}$. Given that $K_{p 2}, K_{i 2}$, and $K_{p v}$ are all negative values in LGVM, both $a$ and $b$ in Eq. (16) are positive, which can guarantee the stability of the closed-loop system [21]. Therefore, the steady-state stability of the dc-bus voltage control in LGVM can be ensured in the developed LVRT scheme.

However, the above conclusion cannot be obtained if the PV panels operate in the left section of the P-V characteristic curve. For example, as discussed above, the PV voltage reference in LGVM increases if $V_{d c}>V_{d c 2}^{*}$. However, the dc-bus voltage may enlarge because of the increasing PV power generated with the increase in PV voltage $V_{p v}$ in the left section of the P-V characteristic curve. Consequently, the left section of the P-V characteristic curve is an unstable region for the proposed LVRT scheme. Although the PV panels may work in the left section of the P-V characteristic curve in the transient process because of abrupt changes of solar irradiation, the proposed technique can fortunately ensure that the steady-state operating point of PV panels always lies in the right section of the P-V characteristic curve or at the MPP in LGVM.

\section{B. Transient Analysis of the Dc-bus Voltage Control in LGVM}

To explore the transient process of the dc-bus voltage control in LGVM, all the possible transient cases are classified into eight types, as shown in Figs. 5 and 6 according to the present PV power $P_{A}$, the present maximum PV power $P_{m p p}$, 
and the allowed maximum grid feeding active power $P_{g \text { max }}$ in Eq. (7). Point A represents the present operating point of PV panels, and point $\mathrm{B}$ is the desired steady-state operating point. In the discussion below, PI_NOR functioning means that the output of PI_NOR does not reach the upper limit, while PI_LVRT functioning means the PI_LVRT output is positive.

In Fig. 5(a), $A$ is in the downhill section of the $P-V$ characteristic curve, and A is forced to move forward to the desired equilibrium B if PI_LVRT is regulating the dc-bus voltage according to the aforementioned discussion. By contrast, the dc-bus voltage increases continuously if the voltage is controlled by PI_NOR because $P_{A}$ is bigger than $P_{g \text { max }}$. However, the PI_LVRT starts to regulate the dc-bus voltage once the dc-bus voltage exceeds $430 \mathrm{~V}$. Subsequently, operating point A moves forward to the anticipated equilibrium $\mathrm{B}$ as well.

Point A in Fig. 5(b) moves forward to the MPP because of the MPPT control if PI_NOR is functioning. The case of Fig. 5(b) can then be converted to the case of Fig. 5(a) after $P_{A}>P_{g \text { max }}$. Consequently, point A can return to and remain at point $\mathrm{B}$ according to the above analysis for Fig. 5(a). Clearly, point A of Fig. 5(b) can arrive and remain at point B if PI_LVRT is functioning at present.

Fig. 5(c) is a particular case of Fig. 5(a) when A is at the MPP. Therefore, the adjusting process of Fig. 5(c) is similar to that in Fig. 5(a).

If PI_LVRT is performing its function, the operating point A of Fig. 6(a) will undoubtedly transfer to equilibrium B. This transfer is caused by the continuous increase of the dc-bus voltage because $P_{A}>P_{g \max }$ forces the output $V_{p v_{-} d c}$ of PI_LVRT to increase continuously. Subsequently, point A is forced to enter into the right side of MPP. Thus, Fig. 6(a) becomes similar to Fig. 5(a), where point $A$ is proven to remain at B in the steady state. Assuming that PI_NOR is functioning in the case of Fig. 6(a), the dc-bus voltage increases because $P_{A}>P_{g \text { max }}$ and PI_LVRT regulates the dc-bus voltage once $V_{d c}$ reaches $430 \mathrm{~V}$. Subsequently, point A also moves to point B.

In Fig. 6(b), point A travels forward to the MPP under the MPPT control if PI_NOR is performing its role. Once $P_{A}>P_{g \text { max }}$, the case of Fig. 6(b) becomes similar to that of Fig. 6(a). While PI_LVRT is functioning, A moves toward the origin as $V_{d c}$ decreases for $P_{A}<P_{g \text { max }}$. However, PI_NOR take its role if the dc-bus voltage drops to $400 \mathrm{~V}$. Point $\mathrm{A}$ then goes to the MPP under the MPPT control, and Fig. 6(b) also becomes similar to Fig. 6(a).

As shown in Figs. 5(d), 6(c), and 6(d), the $P_{g \text { max }}$ curve is above the MPP. The PV inverter can still deliver the total PV power to the grid even in LGVM. Consequently, the PV system can still work in the MPPT mode during low voltage

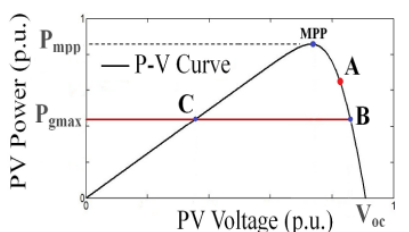

(a) $P_{m p p}>P_{A}>P_{g \max }$

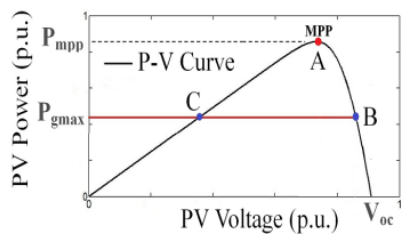

(c) $P_{A}=P_{m p p}>P_{g \text { max }}$

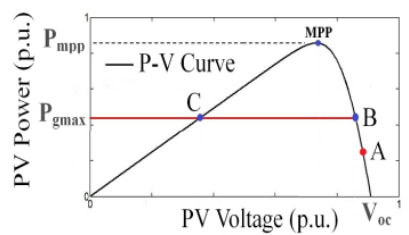

(b) $P_{A}<P_{g \max }<P_{m p p}$

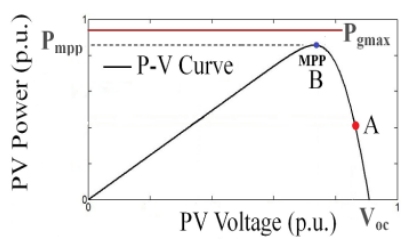

(d) $P_{A}<P_{m p p}<P_{g \text { max }}$
Fig. 5. Cases when $\mathrm{A}$ is in the right section of the $\mathrm{P}-\mathrm{V}$ characteristic curve or at the MPP.

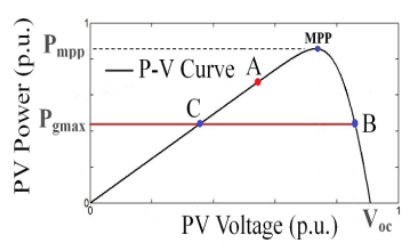

(a) $P_{m p p}>P_{A}>P_{g \text { max }}$

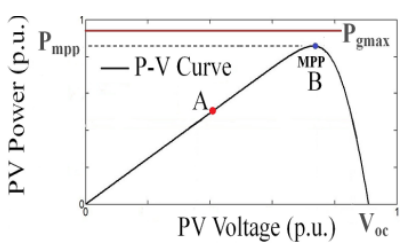

(c) $P_{A}<P_{m p p}<P_{g \text { max }}$

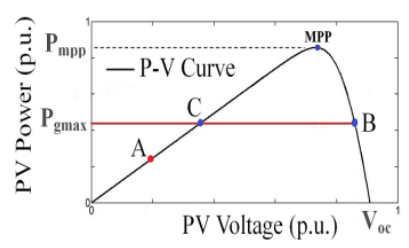

(b) $P_{A}<P_{g \max }<P_{m p p}$

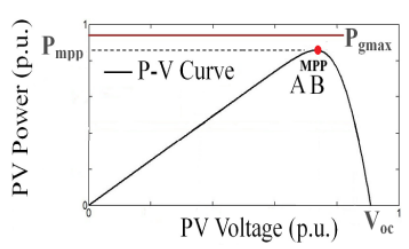

(d) $P_{A}=P_{m p p}<P_{g \text { max }}$
Fig. 6. Cases when $\mathrm{A}$ is in the left section of the $\mathrm{P}-\mathrm{V}$ characteristic curve or at the MPP.

period for the steady-state operating point of PV panel, which stays at the MPP in such cases. In summary, the steady-state operating point of PV panels in LGVM is in the right section of the P-V characteristic curve when $P_{g \text { max }}<P_{m p p}$ or at the MPP if $P_{g \text { max }} \geq P_{m p p}$ regardless of the present operating point of PV panels. Therefore, the proposed LVRT strategy is adaptable to variations of both grid voltage and environmental conditions.

\section{PARAMETER DESIGN}

\section{A. Design of Dc-bus Voltage Reference $V_{d c 2}^{*}$}

As described in previous sections, two different dc-bus voltage references $V_{d c 1}^{*}$ and $V_{d c 2}^{*}$ are used in this paper. The dc-bus voltage is regulated to the voltage reference $V_{d c 1}^{*}$ in NGVM, whereas the voltage is controlled to $V_{d c 2}^{*}$ if 
$P_{g \text { max }}<P_{m p p}$ in LGVM. Given that the dc-bus voltage can potentially increase because of the power imbalance at the presence of grid voltage sag, $V_{d c 2}^{*}$ is set to be larger than $V_{d c 1}^{*}$. With a smaller $V_{d c 2}^{*}$, PI_LVRT can function earlier, such that the proposed LVRT approach can respond to the grid voltage sag fault more quickly. Hence, $V_{d c 2}^{*}$ should be as close to $V_{d c 1}^{*}$ as possible from the perspective of minimum dc-bus peak voltage during sudden grid voltage sag. However, as stated above, the dc-bus voltage contains double line frequency voltage ripples caused by power pulsation on the ac side. In practice, the ripples are limited to $1 \%-5 \%$ nominal dc-bus voltage $\left(V_{d c 1}^{*}=400 \mathrm{~V}\right)$ by choosing suitable capacitance for the dc-bus capacitor $C_{2}$. In this study, $C_{2}=1500 u F$, and the maximum voltage ripples are about $\pm 10 \mathrm{~V}$ when the inverter operates at the rated capacity of the inverter. Thus, the maximum dc-bus voltage is $410 \mathrm{~V}$ in NGVM. Notably, except for the grid voltage sag fault, the dc-bus voltage also increases because of sudden increased solar insolation or other disturbances. To avoid the wrong operation of PI_LVRT, $20 \mathrm{~V}$ voltage margin can be chosen for disturbance rejection. Therefore, the dc-bus voltage reference $V_{d c 2}^{*}$ is chosen to $430 \mathrm{~V}(410 \mathrm{~V}+20 \mathrm{~V}=430 \mathrm{~V})$ in this study.

\section{B. Design of PI_LVRT}

To prevent the inverter from triggering overvoltage protection when grid voltage sag occurs, $K_{p 2}$ and $K_{i 2}$ should be chosen according to the limited dc-bus peak voltage in LGVM. In this study, the limited dc-bus peak voltage is set to $460 \mathrm{~V}$ (the overvoltage protection threshold of the inverter is $480 \mathrm{~V}$ ). The output $V_{p v_{-} d c}$ of PI_LVRT in discrete form can be expressed as

$$
\begin{aligned}
& V_{p v_{-} d c}(k)= 2 V_{p v_{-} d c}(k-1)-V_{p v_{-} d c}(k-2)+m\left[f\left(V_{p v}(k-2)\right)\right. \\
&\left.-f\left(V_{p v}(k-1)\right)\right] T_{c}-n f\left(V_{p v}(k-1)\right) T_{c}^{2} \\
& m=\frac{K_{p 2}}{C_{2} V_{d c 2}^{*}}, n=\frac{K_{i 2}}{C_{2} V_{d c 2}^{*}}
\end{aligned}
$$

where $T_{c}$ is the control period of PI_LVRT. From Eq. (17), the dc-bus voltage can be obtained as

$$
\begin{aligned}
& \Delta V(k)=\Delta V(k-1)+\frac{f\left(V_{p v}(k-1)\right)}{C_{2} V_{d c 2}^{*}} T_{c} . \\
& V_{d c}(k)=V_{d c 2}^{*}+\Delta V(k)
\end{aligned}
$$

According to the simulation results, the performance of PI_LVRT is acceptable if $K_{p 2}=10 K_{i 2}$. Thus, only one parameter $K_{i 2}$ requires adjustment. The maximum dc-bus peak voltage appears in the case where the PV panels operate at rated capacity and the grid voltage drops below 50\% nominal value. Given that the grid feeding active power
TABLE I

SiMUlATED SySTEM SPECIFICATIONS

\begin{tabular}{lc}
\hline \multicolumn{1}{c}{ Parameters } & Value \\
\hline MPP voltage of PV panels $\left(V_{m}\right)$ & $250 \mathrm{~V}$ \\
MPP current of PV panels $\left(I_{m}\right)$ & $12 \mathrm{~A}$ \\
Open-circuit voltage of PV panels $\left(V_{o c}\right)$ & $350 \mathrm{~V}$ \\
Short-circuit current of PV panels $\left(I_{s c}\right)$ & $16 \mathrm{~A}$ \\
Grid voltage $\left(V_{g}\right)$ & $220 \mathrm{~V}$ \\
grid angular frequency $\left(\omega_{f}\right)$ & $314 \mathrm{rad} / \mathrm{s}$ \\
Rated grid-connected current in RMS $\left(I_{r}\right)$ & $15 \mathrm{~A}$ \\
Input capacitor $\left(C_{1}\right)$ & $100 \mathrm{uF}$ \\
Dc-bus capacitor $\left(C_{2}\right)$ & $1,500 \mathrm{uF}$ \\
Inductors $\left(L_{1}, L_{2}, L_{3}\right)$ & $3 \mathrm{mH}$ \\
Switching frequency $\left(f_{s}\right)$ & $10 \mathrm{kHz}$ \\
Voltage reference for PI_NOR $\left(V_{d c 1}^{*}\right)$ & $400 \mathrm{~V}$ \\
Voltage reference for PI_LVRT $\left(V_{d c 2}^{*}\right)$ & $430 \mathrm{~V}$ \\
Voltage step of P\&O $(\Delta V)$ & $1 \mathrm{~V}$ \\
PI_NOR $\left(K_{p 1}, K_{i 1}\right)$ & $1.0,0.02$ \\
PI_LVRT $\left(K_{p 2}, K_{i 2}\right)$ & -4.5, \\
PI_PV $\left(K_{p 3}, K_{i 3}\right)$ & -0.45 \\
PR $\left(K_{p}, K_{r 1}\right)$ & $0.2,0.03$ \\
Control period of PI_LVRT $\left(T_{c}\right)$ & $15,2,000$ \\
\hline
\end{tabular}

becomes zero when the grid voltage is below 50\% nominal value according to Fig. 2(b), all the generated PV power should be stored in the dc-bus capacitor during the transient period. The maximum dc-bus peak voltage can be calculated through Eqs. (17) and (18). If the voltage is larger than $460 \mathrm{~V}$, then $K_{i 2}$ should be decreased (absolute value of $K_{i 2}$ increases because $K_{i 2}$ is negative in this study) until the calculated maximum dc-bus peak voltage is below $460 \mathrm{~V}$. A smaller dc-bus peak voltage can be achieved with a smaller $K_{i 2}$, but the transient process lengthens. Therefore, a bigger $K_{i 2}$ is better as long as the maximum dc-bus peak voltage is within the limited value.

\section{Simulation Results}

The case study is based on a single-phase two-stage grid-connected PV system. The particular parameters of the system are listed in Table I.

Fig. 7(a) depicts the simulation, where the grid voltage drops to $149 \mathrm{~V}$ from $220 \mathrm{~V}$ at $0.3 \mathrm{~s}$ and is restored at $0.7 \mathrm{~s}$. Obviously, the dc-bus voltage $V_{d c}$ increases at $0.3 \mathrm{~s}$. Once the dc-bus voltage reaches $430 \mathrm{~V}, V_{p v_{-} d c}$ starts to increase, while $V_{p v_{-} m p p t}$ remains unchanged. Subsequently, the dc-bus voltage is regulated to stay at $430 \mathrm{~V}$ in the steady state during the fault period. Moreover, the maximum PV power is 

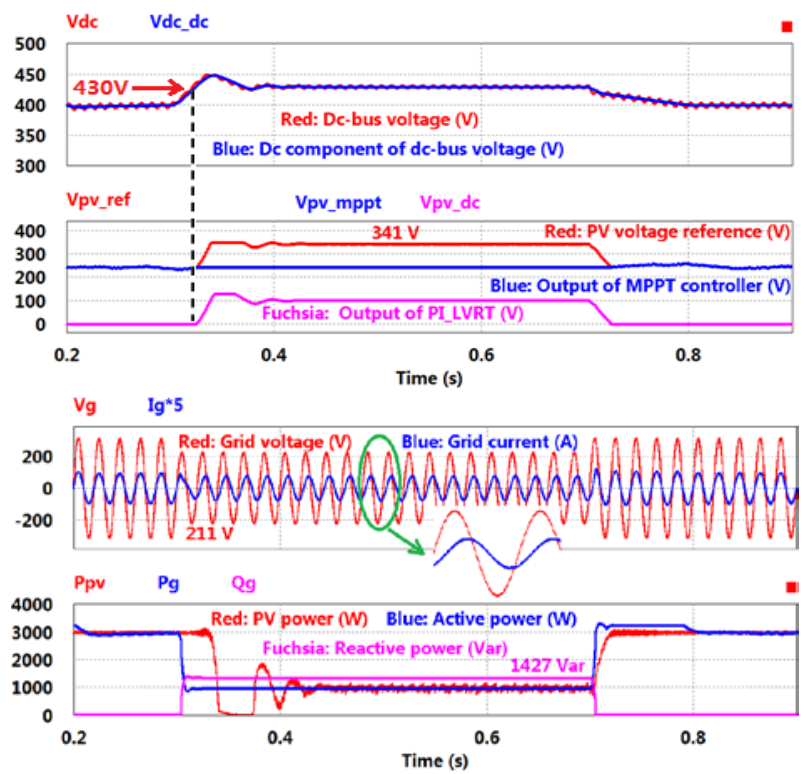

(a)
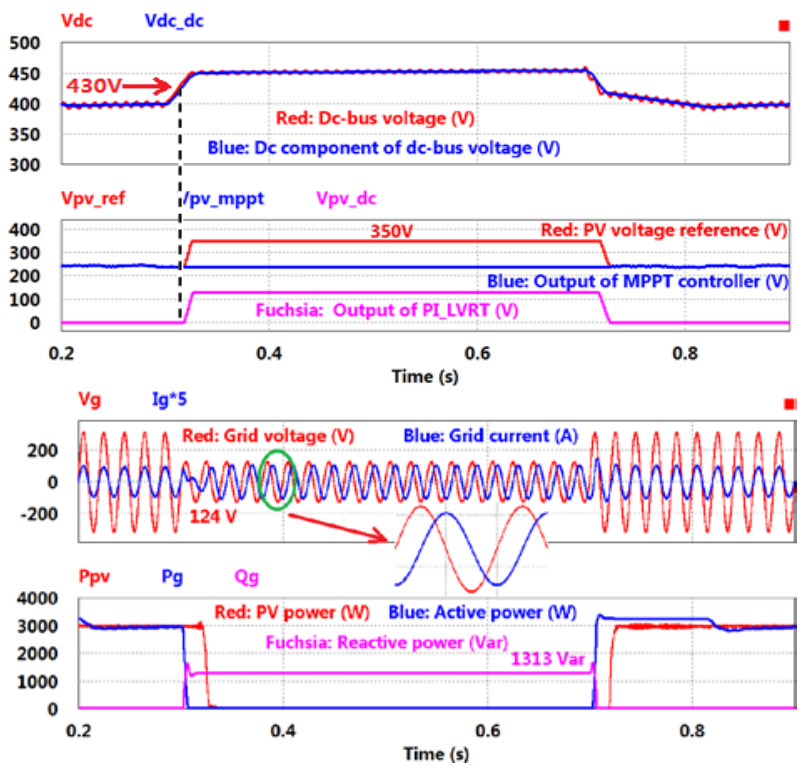

(b)

Fig. 7. (a) LVRT simulation I with the proposed LVRT strategy. (b) LVRT simulation II with the proposed LVRT strategy.

achieved instantly when the output $V_{p v_{-} d c}$ of PI_LVRT decreases to zero during the recovery process. Afterwards, the PI_NOR controls the dc-bus voltage again when $V_{d c}$ drops to $400 \mathrm{~V}$. Before $0.3 \mathrm{~s}$, the grid current is in phase with the grid voltage, whereas the grid current lags behind the grid voltage during the low voltage period. As shown in Fig. 7(a), the reactive power is $1,427 \mathrm{Var}$ and the corresponding reactive current is 9.6 A, which agrees well with the required reactive current of 9.7 A calculated via Eq. (3).

In Fig. 7(b), the grid voltage drops to $88 \mathrm{~V}$ from $220 \mathrm{~V}$ at $0.3 \mathrm{~s}$ and restores at $0.7 \mathrm{~s}$. The response process in Fig. 7(b) is similar to that in Fig. 7(a). However, the dc-bus voltage
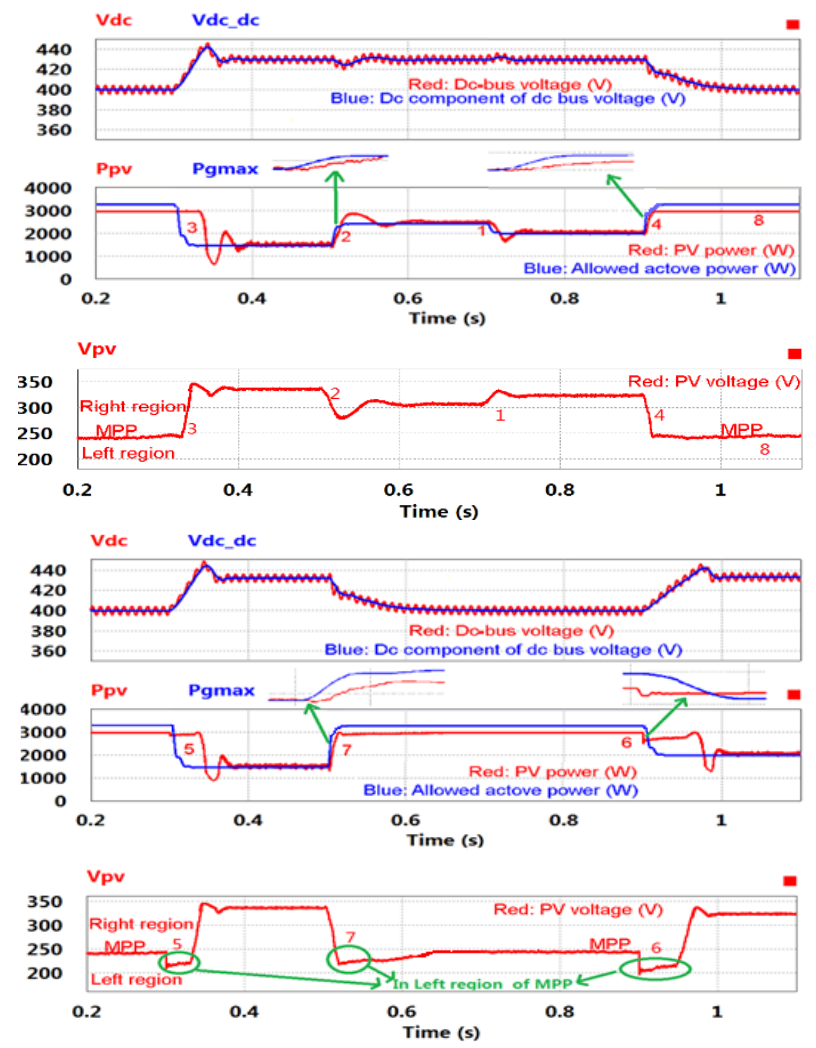

Fig. 8. Transient processes with the proposed LVRT strategy.

increases to and stays at $450 \mathrm{~V}$ during the fault period in Fig. 7(b). Surplus solar energy during the transient process forces the dc-bus voltage to increase to $450 \mathrm{~V}$. Afterwards, the dc-bus voltage remains constant at $450 \mathrm{~V}$ because the PV inverter provides zero active power to the grid in LGVM. Fortunately, the dc-bus voltage at $450 \mathrm{~V}$ is within the limited value of $460 \mathrm{~V}$. The design of PI_LVRT is proven to satisfy the requirement. Both Figs. 7(a) and 7(b) also show that the maximum PV power can be achieved quickly after the fault. Most importantly, the outputs of the MPPT controller and the PI_LVRT have no sudden changes during the entire transition period. Therefore, a smooth transition from NGVM to LGVM or from LGVM to NGVM can be realized in this study.

Fig. 8 presents the transient responses to the cases in Figs. 5 and 6. Numbers 1, 2, 3, and 4 represent Figs. 5(a), 5(b), 5(c), and 5(d), respectively; while numbers $5,6,7$, and 8 stand for Figs. 6(a), 6(b), 6(c), and 6(d). The symbol MPP on the figure represents the PV voltage at the MPP of the PV panels. As shown in Fig. 8, the steady-state dc-bus voltage always remains at $400 \mathrm{~V}$ or $430 \mathrm{~V}$. Moreover, in the steady state, the PV voltage is always in the right section of the MPP even though the transient operating point of the PV panels enters into the left section of the MPP in cases 1, 2, 3, 5, and 6. In cases 4, 7, and 8 , the PV panels operate at the MPP in the steady state because the allowable maximum grid feeding active power is 


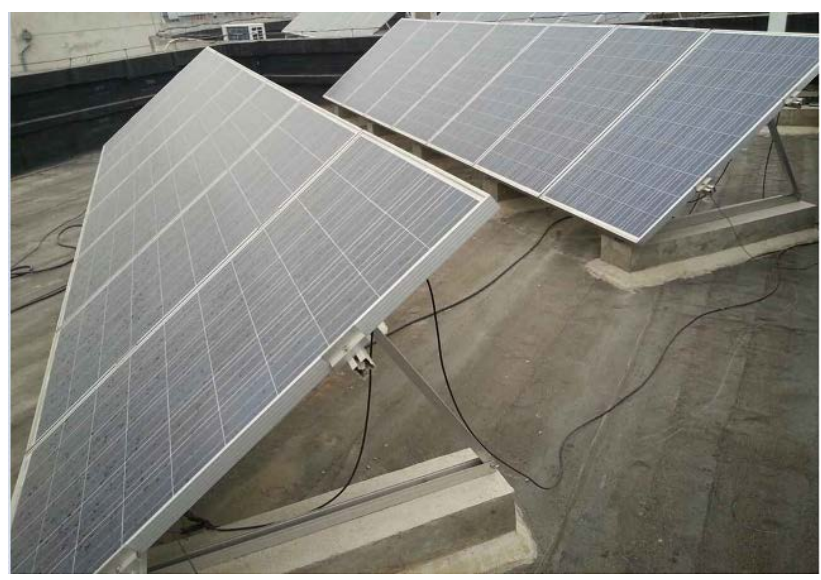

(a)

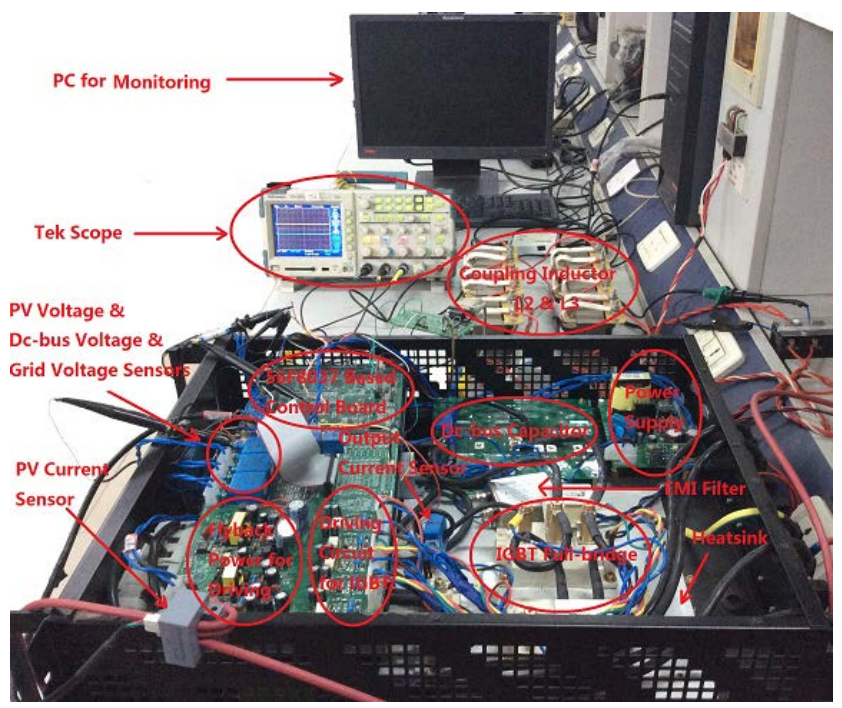

(b)

Fig. 9. The experimental setup. (a) $3 \mathrm{~kW}$ PV arrays. (b) Inverter.

more than the present maximum power of the PV panels. The simulation results agree well with the theoretical analysis in Section III(B) and justify that the dc-bus voltage can be well controlled with the proposed control method in both NGVM and LGVM.

\section{EXPERIMENTAL RESULTS}

To validate the proposed LVRT technique, the laboratory prototype shown in Fig. 9 is built. The particular parameters of the prototype are given in Table I. In Fig. 9(a), the PV array consists of $14 \mathrm{PV}$ panels. Seven PV panels are in a series to form a group of PV arrays, and then two groups are connected in parallel. The open-circuit voltage of each PV panel is about $45 \mathrm{~V}$, the short-circuit current is about $8 \mathrm{~A}$, and the rated power is about $220 \mathrm{~W}$. DSP chip 56F8037 is used to implement the proposed LVRT strategy.

The PV voltage, current, and power during the MPPT process in NGVM is depicted in Fig. 10. Seeking the maximum power of the PV panels clearly takes about $0.4 \mathrm{~s}$.

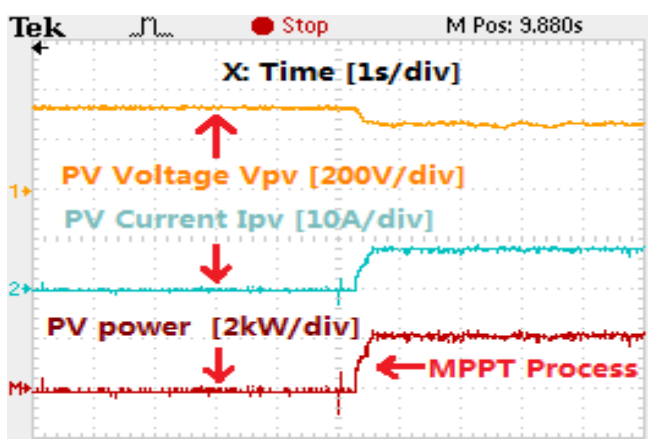

Fig. 10. MPPT process in NGVM.

The present maximum PV power of the PV panels is about $2.2 \mathrm{~kW}$, while the PV voltage and current at the MPP are around $250 \mathrm{~V}$ and $8 \mathrm{~A}$ respectively.

In Fig. 11(a), the grid voltage drops to $149 \mathrm{~V}$ from $220 \mathrm{~V}$ and restores after $0.7 \mathrm{~s}$, while the voltage drops to $88 \mathrm{~V}$ from $220 \mathrm{~V}$ and restores after $0.7 \mathrm{~s}$ in Fig. 11(b). The PV power decreases to $600 \mathrm{~W}$ from about $2.3 \mathrm{~kW}$ in Fig. 11(a), whereas that in Fig. 11(b) decreases to $0 \mathrm{~kW}$ from $2.6 \mathrm{~kW}$. During the fault period, the steady-state dc-bus voltage in Fig. 11(a) is well regulated to $430 \mathrm{~V}$, but the voltage remains at $450 \mathrm{~V}$ in Fig. 11(b). As mentioned earlier, the dc-bus voltage cannot be regulated to $430 \mathrm{~V}$ during the fault period because the PV inverter provides zero active power in Fig. 11(b). Fortunately, the dc-bus peak voltage is below the limited value of $460 \mathrm{~V}$. The provided reactive power of the PV inverter during the fault period in Figs. 11(a) and 11(b) are 1,371 Var ( $13 A \times 211 V \div 2=1371$ Var ) and 1,240 Var ( $20 A \times 124 V \div 2=1240$ Var ) respectively, which agree well with the simulations. Therefore, the experimental results demonstrate the feasibility of the proposed LVRT method.

The experiment with the conventional LVRT strategy when the grid voltage drops to $149 \mathrm{~V}$ from $220 \mathrm{~V}$ and restores after $0.7 \mathrm{~s}$ is described in Fig. 11(c). The experiment where the grid voltage drops to $88 \mathrm{~V}$ from $220 \mathrm{~V}$ and restores after $0.7 \mathrm{~s}$ is shown in Fig. 11(d). The transient process in Fig. 11(a) is much smoother than that in Fig. 11(c). Moreover, the power pulsation in Fig. 11(c) caused by a sudden grid voltage drop in the conventional LVRT approach does not occur in Fig. 11(a). The dc-bus voltage drop of about $100 \mathrm{~V}$ in Fig. 11(d) during the recovery process is also adverse for the stability of the system because the conventional LVRT method has to restart the MPPT control from the non-MPPT control and cannot achieve enough PV power instantly. Given that the auxiliary power system is generally powered by the dc-bus, a dc-bus voltage drop that is too large may lead to the power outage of the auxiliary power system, which threatens the safety of the PV inverter. Therefore, the recovery process without a dc-bus voltage drop in Fig. 11(b) is superior to that in Fig. 11(c).

To test the stability of the dc-bus voltage in LGVM, the 


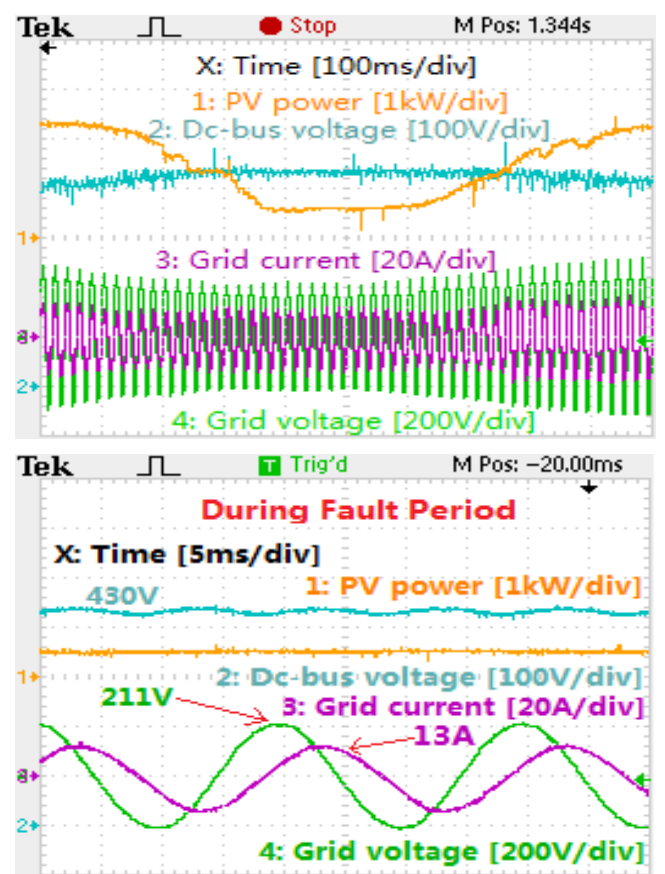

(a)
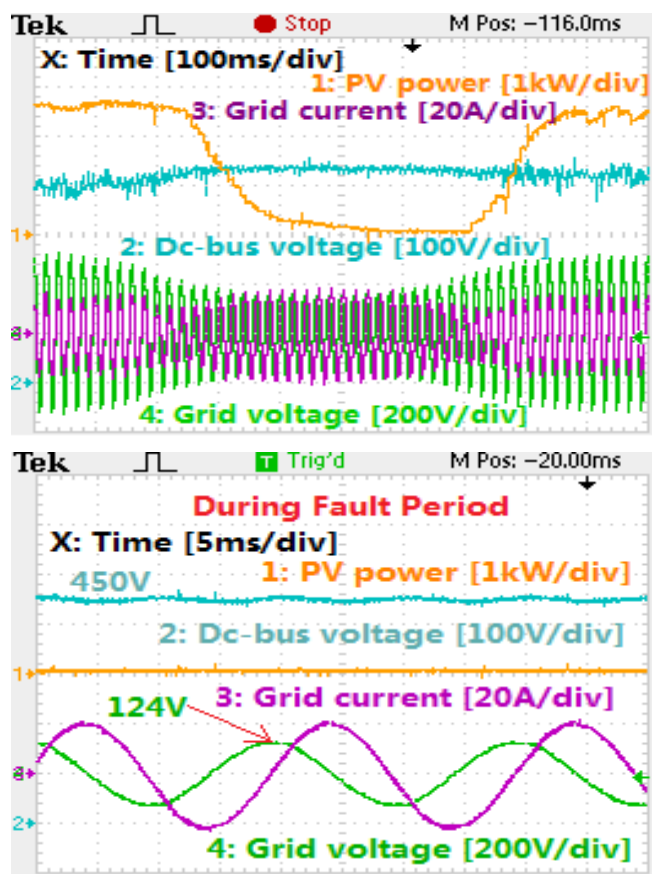

(b)

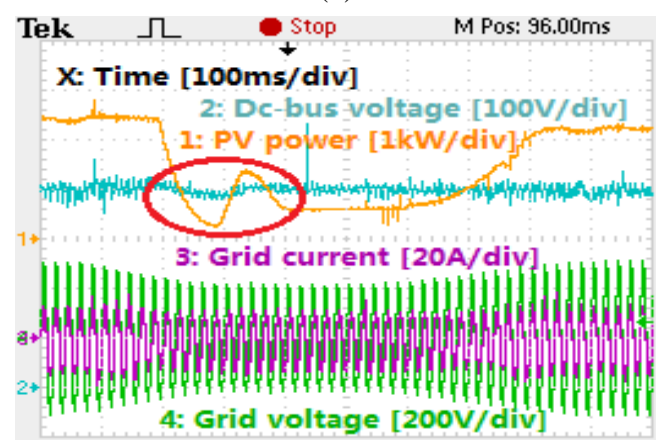

(c)

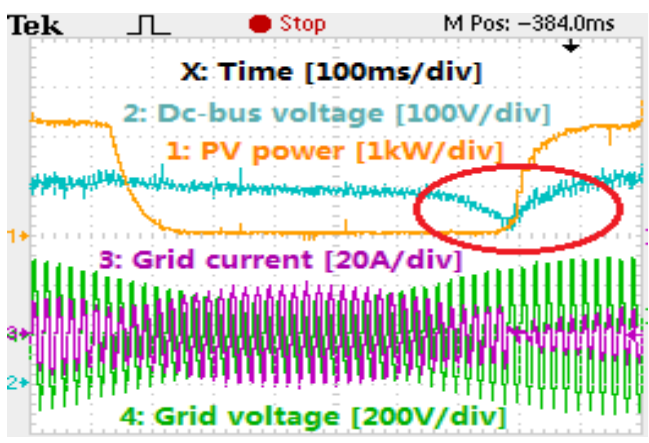

(d)

Fig. 11. (a) Experiment I with the proposed LVRT strategy. (b) Experiment II with the proposed LVRT strategy. (c) Experiment III with the conventional LVRT strategy. (d) Experiment IV with the conventional LVRT strategy.

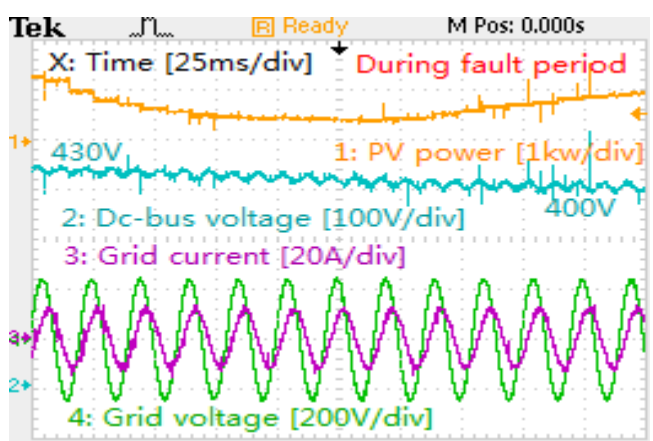

(a)

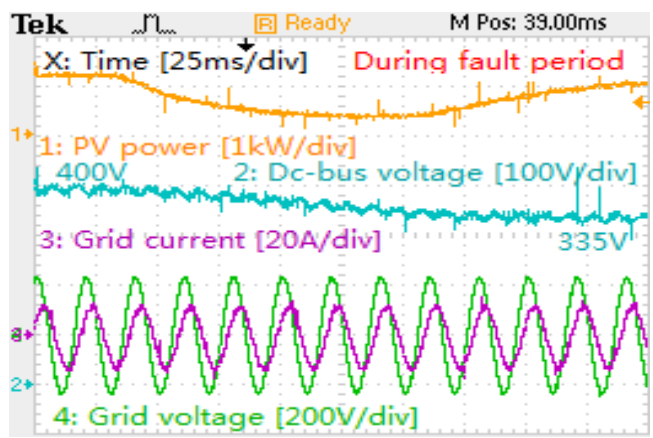

(b)

Fig. 12. (a) Experiment V with the proposed LVRT strategy. (b) Experiment VI with the conventional LVRT strategy.

sudden decrease in solar insolation during the fault period is applied to both developed LVRT approach; the conventional strategy and experimental results are presented in Figs. 12(a) and 12(b) respectively. The power drop from the decrease in solar insolation is about $800 \mathrm{~W}$ in both Figs. 12(a) and 12(b). According to Fig. 12(a), the dc-bus voltage can still be regulated to stay at $400 \mathrm{~V}$ although the voltage decreases from $430 \mathrm{~V}$ as the solar insolation decreases. Nevertheless, the dc-bus voltage can no longer be maintained at the reference of $400 \mathrm{~V}$ during the fault period in Fig. 12(b). The dc-bus voltage drop in Fig. 12(b) is about $65 \mathrm{~V}$, which increases as the PV power drop grows, threatening the safety of the PV inverter as well. In summary, the conventional LVRT strategy can 
effectively address the dc-bus overvoltage problem during grid voltage sag. However, this strategy cannot guarantee the stabilization of the dc-bus voltage in cases of decreasing solar insolation in LGVM. With adaptability to varying environmental conditions, the LVRT scheme created can thus regulate the dc-bus voltage effectively and guarantee the safety of PV inverters in LGVM.

\section{CONCLUSION}

A smooth LVRT control method for single-phase two-stage grid-connected PV inverters was presented in this paper. With the proposed LVRT approach, the LVRT capability of the single-phase two-stage grid-connected PV inverter can be enhanced with better transient performance and stability. The detailed analysis of the developed LVRT strategy was given. Finally, the simulation and experimental results corroborated the feasibility of the proposed LVRT technique.

\section{REFERENCES}

[1] K. O. Kovanen, "Photovoltaics and power distribution," Renewable Energy Focus, Vol. 14, No. 3, pp. 20-21, May/Jun. 2013.

[2] Y. Bae, T. K. Vu, and R. Y. Kim, "Implemental control strategy for grid stabilization of grid-connected PV system based on German grid code in symmetrical low-to-medium voltage network,” IEEE Trans. Energy Convers., Vol. 28, No. 3, pp. 619-631, Sep. 2013.

[3] IEEE Guide for Design, Operation, and Integration of Distributed Resource Island Systems with Electric Power Systems, IEEE Std 1547.4-2011, 2011.

[4] I. Erlich and U. Bachmann, "Grid code requirements concerning connection and operation of wind turbines in Germany,” IEEE Power Engineering Society General Meeting, pp. 1253-1257, 2005.

[5] “Grid Code High and extra high voltage,” E. ON Netz GmbH, Bayreuth, 2006.

[6] R., Majumder, "Aspect of voltage stability and reactive power support in active distribution," IET Generation, Transmission \& Distribution, Vol. 8, No. 3, pp. 442-450, Sep. 2013.

[7] A. Marinopoulos, F. Papandrea, M. Reza, S. Norrga, F. Spertino, and R. Napoli, "Grid integration aspects of large solar PV installations: LVRT capability and reactive power/voltage support requirements," IEEE Power Tech Conference, pp. 1-8, 2011.

[8] S. Cobreces, E. Bueno, F. J. Rodriguez, F. Huerta, and P. Rodriguez, "Influence analysis of the effects of an inductive-resistive weak grid over L and LCL filter current hysteresis controllers," IEEE Power Electronics and Applications European Conference, pp. 1-10, 2007.

[9] G. Liu, Y. Yang, P. Wang, W. Wang, and D. Xu, "Stability control method based on virtual inductance of grid-connected PV inverter under weak grid," Industrial Electronics Society, IECON 39th Annual Conference of IEEE, pp. 1867-1872, 2013.

[10] X. Bao, P. Tan, F. Zhuo and X. Yue, "Low voltage ride through control strategy for high-power grid connected photovoltaic inverter," Applied Power Electronics Conference and Exposition (APEC), Twenty-Eighth Annual IEEE, pp. 97-100, 2013.

[11] C. M. Lin, C. M. Young, W. S. Yeh, and Y. H. Liu, “An LVRT control strategy for reducing Dc-bus voltage fluctuation of a two-stage photovoltaic multilevel inverter," IEEE 10th International Power Electronics and Drive Systems (PEDS) Conference, pp. 908-913, 2013.

[12] G. M. S. Islam, A. Al-Durra, S. M. Muyeen, and J. Tamura, "Low voltage ride through capability enhancement of grid connected large scale photovoltaic system,” Industrial Electronics Society, IECON 2011-37th Annual IEEE, pp. 884-889, 2011.

[13] H. Tian, F. Gao, and C. Ma, "Novel low voltage ride through strategy of single-stage grid-tied photovoltaic inverter with supercapacitor coupled," IEEE 7th International Power Electronics and Motion Control (IPEMC) Conference, pp. 1188-1192, 2012.

[14] Y. S. Wu, C. H. Chang, Y. M. Chen, C. S. Cheng, C. W. Liu, and Y. R. Chang, "The current control of PV inverter for low voltage ride through," 15th International Power Electronics and Motion Control (EPE/PEMC) Conference, pp. 4-6, 2012.

[15] Y. Yang, F. Blaabjerg, and H. Wang, "Low-voltage ride-through of single-phase transformerless photovoltaic inverters,” IEEE Trans. Ind. Appl., Vol. 50, No. 3, pp. 1942-1952, May/Jun. 2014.

[16] Y. Yang, F. Blaabjerg, and Z. Zou, "Benchmarking of grid fault modes in single-phase grid-connected photovoltaic systems," IEEE Trans. Ind. Appl., Vol. 49, No. 5, pp. 2167-2176, Sep./Oct. 2013.

[17] A. Nagliero, R. A. Mastromauro, M. Liserre, and A. Dell'Aquila, "Monitoring and synchronization techniques for single-phase PV systems," Power Electronics Electrical Drives Automation and Motion (SPEEDAM), International Symposium IEEE on, pp. 1404-1409, 2010.

[18] W. Chen and J. Lin, “One-dimensional optimization for proportional resonant controller design against the change in source impedance and solar irradiation in PV systems," IEEE Trans. Ind. Electron., Vol. 61, No. 4, pp. 1845-1854, Apr. 2014.

[19] C. Hua, J. Lin, and C. Shen, "Implementation of a DSP-controlled photovoltaic system with peak power tracking,” IEEE Trans. Ind. Electron., Vol. 45, No. 1, pp. 99-107, Feb. 1998.

[20] Y. Liu, H. Xin, Z. Wang, and T. Yang, "Power control strategy for photovoltaic system based on the Newton quadratic interpolation," IET Renewable Power Generation, Vol. 8, No. 6, pp. 611-620, Nov. 2014.

[21] S. A. Khajehoddin, M. Karimi-Ghartemani, P. K. Jain, and A. Bakhshai, "Dc-bus design and control for a single-phase grid connected renewable converter with a small energy storage component," IEEE Trans. Power Electron., Vol. 28, No. 7, pp. 3245-3254, Jul. 2013.

[22] H. Bin and D. Liu, "Modeling of a large-scale photovoltaic generation and analysis of its security and stability operation in west-qinghai grid," IEEE Third Intelligent System Design and Engineering Applications (ISDEA) International Conference, pp. 958-962, 2013. 


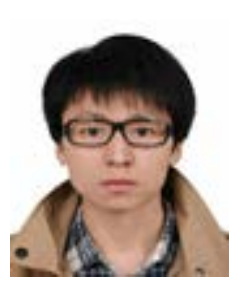

Furong Xiao was born in Jiangxi, China, in 1989. He received his B.S. degree in Electrical Engineering from Beijing Institute of Technology, China, in 2011. He is currently pursuing his Ph.D. degree in the School of Automation, Beijing Institute of Technology. His research interests include power electronic converters, control of inverters, renewable energy systems, and microgrids.

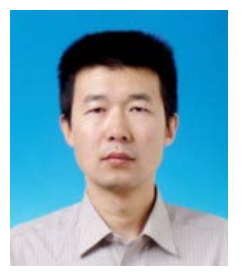

Lei Dong was born in China in 1967. He received his B.S. and Ph.D. degrees from Nanjing University of Aeronautics and Astronautics, China, in 1990 and 2000 respectively. He worked as a post-doctoral in Tsinghua University, China, from 2000 to 2002. He joined AVIC-The First Aircraft Institute as an Engineer from 1990 to 1995. At present, he is an associate professor in the Beijing Institute of Technology China and the director of the Power Electronics and Motion Control Research Center of the university. His research interests include power electronics and motion control, microgrids, and renewable energy.

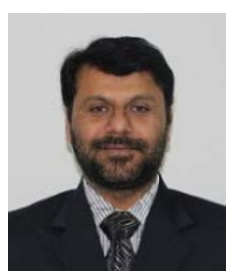

Shahnawaz Farhan Khahro was born in Hyderabad, Sindh, Pakistan. He received his B.E. (Electronics) and M.E. (CSN) degrees from Mehran University of Engineering and Technology, Jamshoro Sindh Pakistan in 2002 and 2007, respectively. He received his Ph.D. degree in Renewable Energy Conversion and Control Strategies from the Beijing Institute of Technology (BIT), Beijing, PR China in 2014. From 1999 to 2004, he worked in the Civil Aviation Authority in Pakistan, and from 2004 to 2008, he worked at Pakistan Telecommunication Company Ltd. In November 2008, he joined the Environment and Alternative Energy Department, Government of Sindh, Pakistan, as Assistant Director. Since January 2015, Mr. Khahro has been serving as the Deputy Director (Alternative Energy) of the Energy Department, Government of Sindh in Pakistan. His research interests include renewable energy power conversion systems, DC-DC converters, power electronic converters, and application of power electronics in renewable energy systems.

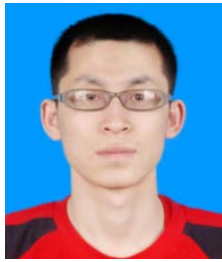

Xiaojiang Huang was born in China in 1985. He received his B.S. degree in Electrical Engineering and Automation from Beijing Institute of Technology, Beijing, China in 2009. He is currently pursuing his Ph.D. degree in the School of Automation, Beijing Institute of Technology. His research interests include power electronics and control, renewable energy systems, and smart grids.

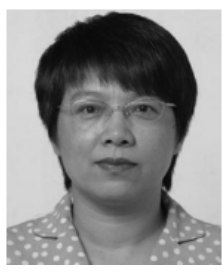

Xiaozhong Liao was born in China in 1962. She received her B.S. and M.S. degrees in Electrical Engineering from Tianjin University, Tianjin, China, in 1982 and 1984 respectively. She received her Ph.D. degree in Control Sciences and Engineering from Beijing Institute of Technology, Beijing, China, in 2004. She was a visiting researcher in the Department of Electrical and Electronic Engineering, University of Central Lancashire, Preston, U.K., from 1995 to 1996. She is now the associate dean and a full-time professor at the School of Automation, Beijing Institute of Technology, Beijing, China. Her research interests are in the fields of power electronics, motor drives, and renewable energy power conversion. 